\title{
Birth weight and cognitive function at age 11 years: the Scottish Mental Survey 1932
}

\author{
S D Shenkin, J M Starr, A Pattie, M A Rush, L J Whalley, I J Deary
}

\begin{abstract}
Aims-To examine the relation between birth weight and cognitive function at age 11 years, and to examine whether this relation is independent of social class.

Methods-Retrospective cohort study based on birth records from 1921 and cognitive function measured while at school at age 11 in 1932. Subjects were 985 live singletons born in the Edinburgh Royal Maternity and Simpson Memorial Hospital in 1921. Moray House Test scores from the Scottish Mental Survey 1932 were traced on 449 of these children.

Results-Mean score on Moray House Test increased from 30.6 at a birth weight of $<2500 \mathrm{~g}$ to 44.7 at $4001-4500 \mathrm{~g}$, after correcting for gestational age, maternal age, parity, social class, and legitimacy of birth. Multiple regression showed that $15.6 \%$ of the variance in Moray House Test score is contributed by a combination of social class $(6.6 \%)$, birth weight $(3.8 \%)$, child's exact age $(2.4 \%)$, maternal parity $(2.0 \%)$, and illegitimacy $(1.5 \%)$. Structural equation modelling confirmed the independent contribution from each of these variables in predicting cognitive ability. A model in which birth weight acted as a mediator of social class had poor fit statistics.

Conclusion-In this 1921 birth cohort, social class and birth weight have independent effects on cognitive function at age 11. Future research will relate these childhood data to health and cognition in old age.

(Arch Dis Child 2001;85:189-197)
\end{abstract}

Keywords: birth weight; Barker hypothesis; social class; intelligence

Intelligence is determined by a combination of genetic and environmental influences, the relative contributions of which are not yet established, and may vary over the lifespan. ${ }^{1}$ Environmental influences originate while the fetus is developing in utero. The "fetal origins" or "programming" hypothesis ${ }^{23}$ proposes that these influences cause permanent changes in the developing child, resulting in low birth weight, and a predisposition to chronic disease in adult life. The mechanism of this relation is suggested to be fetal undernutrition, with even brief periods of undernutrition during critical periods of rapid cell division causing permanent changes in various organs. ${ }^{2}$ Malnutrition in utero affects brain development, ${ }^{4}$ and the relation between birth weight and cognitive function has therefore been studied.

It has been known for many years that "low birth weight" or intrauterine growth restricted babies fare less well on various measures of mental development in later life. ${ }^{5}$ Many studies have compared low birth weight babies $(<2500 \mathrm{~g})$ with controls, showing impairment in various neurodevelopmental tests up to age $11 .^{5-7}$ Recent large longitudinal cohorts have allowed assessment of the relation between birth weight differences within the normal range and later differences in cognitive function. $^{8-11}$ These show that lower birth weight is associated with lower scores on tests of cognitive function at age 8 in the general population, ${ }^{8}$ and at age $17-18$ in army recruits. ${ }^{9}{ }^{10}$ A relation between birth weight and cognitive function was also seen through childhood to middle life, ${ }^{8}$ but was largely explained by the influence of birth weight on cognition at 8 years. A study of older adults (mean age 60.9), which estimated early life mental ability, found the association between birth weight and cognitive function to be not significant ${ }^{11}$ (corrected for age and social class). Martyn et al therefore suggest that fetal growth is less important than genetic factors and postnatal environmental influences in determining adult cognitive performance. $^{11}$

A recent review concluded that intrauterine growth restriction had little clinically significant effect on mental performance in childhood or adolescence, but was a useful surrogate for social deprivation. ${ }^{12}$

Much of the criticism surrounding the programming hypothesis concerns the confounding influence of factors other than fetal undernutrition operating perinatally and throughout life. ${ }^{13}$ In particular, the socioeconomic environment in which a child is conceived and develops will have an effect on both their physical $^{14}$ and mental ${ }^{13}$ development. Another important potential confounding factor between birth weight and mental ability is gestational age: without this information, many studies have been unable to distinguish low birth weight caused by prematurity from "small for gestational age" or "intrauterine growth restriction". ${ }^{15}$ When investigating early life influences on cognitive development, it is therefore important to consider the combination of birth weight and gestational age. ${ }^{16}$ The relation between birth weight and 
placental weight ${ }^{17}$ might also be relevant. There is also a suggestion of a non-linear relation between birth weight and intelligence, with relatively low cognitive performance at the highest birth weights. ${ }^{9} 10$

There is therefore a need for further studies of birth weight and childhood intelligence to address these issues. Furthermore, if studies from different historical time periods find a consistent relation, this will increase the generalisability of their conclusions. Here we report on a well characterised sample from a distinct historical period. The sample's cognitive function at age 11 may be compared with that of all 11 year old children in Scotland as a result of the Scottish Mental Survey 1932; gestational age can be calculated; and there is information on socioeconomic status. We tested the competing hypotheses that birth weight: (1) is related to cognitive function at age 11 independent of socioeconomic status; and (2) acts as a mediator of the effect of socioeconomic status on cognitive function at age 11 . We also assessed the contribution of other features of the child (for example, gestational age, placental weight, age at cognitive test) and mother (age, parity) to later cognitive function.

\section{Subjects and methods}

BIRTH DATA

Detailed records of all admissions to the Edinburgh Royal Maternity and Simpson Memorial Hospital in Scotland have been retained in the Lothian Health Services Archive at the University of Edinburgh. The records for 1921 include date of birth, last menstrual period (from which gestational age can be calculated), previous pregnancies, maternal age and address, paternal occupation (if father known), birth weight and length, and placental weight. The records for admissions not relating to a live delivery were excluded, as were records for twins. This left 985 live singleton births.

MENTAL ABILITY DATA AGE 11

The Scottish Mental Survey was administered under the auspices of the Scottish Council for Research in Education (SCRE) to all children in Scotland at school on 1 June 1932, and born in 1921 ( $\mathrm{n}=87498 ; 44210$ boys, 43288 girls). ${ }^{18}$ This test was closely related to the Moray House Test Number 12 used in the "11-plus" in England, and will be referred to hereafter as the Moray House Test (MHT). Only a small number of children at private schools, or those absent because of sickness, were not tested. The maximum possible Moray House Test score was 76, from 71 items. The scores were concurrently validated by individually retesting a representative sample of 1000 children on the Stanford Revision of the Binet-Simon Scale $(r=0.8) .{ }^{19}$ SCRE made the complete set of 1932 data available for these analyses.

Hospital birth records from 1921 were matched with subjects' records from the Scottish Mental Survey 1932. The subject's full name was identified by tracing the original birth certificate, and a match was confirmed when full name and date of birth were identical. A match was obtained in 449 cases (45.6\%).

\section{STATISTICAL ANALYSES}

Birth weight and other variables, even when they were distributed along continua, were divided into categories in some analyses for the purposes of description and comparison with previous studies. ${ }^{9-11}$ Models of association were tested initially by partial correlation, with birth measurements used as continuous, not categorical variables. These are reported initially unadjusted, and then adjusted for gestational age, maternal age, parity (total number of previous pregnancies), legitimacy of birth, exact age (in days), and social class. Social class was assigned from the husband's stated occupation (if available) according to the standard occupational classification for the Office of Population Censuses and Surveys (OPCS 1990) and by the General Register Office Classification of Occupations. Analysis by both methods gave similar results (available from the authors) and the General Register Office Classification is reported here. Legitimacy of birth was included as a surrogate social class variable, as no social class could be allocated where the father was not known. It is likely that an unmarried woman with a child in the 1920 s would suffer greater social disadvantage than she would today. Stepwise multiple linear regression analysis was performed, with Moray House Test score as the dependent variable. All independent variables significant at the 0.05 level were added to the models. Results for male and female children were calculated separately and in combination. In view of previous reports of a decline in mental ability in those with highest birth weights, ${ }^{9}$ the data were re-examined, setting a birth weight limit of $4200 \mathrm{~g}$ (the point after which intelligence score was not related to birth weight in Sorensen et al). ${ }^{9}$ Data were analysed using the SPSS statistical software package (SPSS version 10.0; SPSS Inc., Chicago, Illinois, USA, 1999). Structural equation modelling was performed using the EQS programme $^{20}$ to test competing hypotheses concerning the effects of birth weight and socioeconomic status on mental ability at age 11.

\section{Results}

DESCRIPTIVE STATISTICS

The performance of the sample on the MHT ( $\mathrm{n}=449$ : 246 boys, 203 girls; mean MHT score 36.9, SD 14.9) was significantly better than the general Scottish population (mean MHT score 34.5, SD 15.5; p < 0.001), although the effect size of the difference was small (table 1). Therefore, the present sample is not unusual with respect to the population's mean and spread of mental ability test scores at age 11 years. Table 2 divides the hospital births into those whose scores were traced, and those whose scores were not. Of the children whose scores were traced, $54.8 \%$ were male, compared with $47.6 \%$ of the total 
Table 1 Comparison of Moray House Test scores: sample born in Royal Maternity and Simpson's Memorial Hospital, and Scotland

\begin{tabular}{|c|c|c|c|c|c|c|}
\hline & \multicolumn{2}{|l|}{ Male } & \multicolumn{2}{|l|}{ Female } & \multicolumn{2}{|l|}{ Total } \\
\hline & Sample & Scotland & Sample & Scotland & Sample & Scotland \\
\hline Number (\%) & $246(54.8)$ & $44210(50.5)$ & $203(45.2)$ & 43288 (49.5) & 449 & 87498 \\
\hline Mean $(95 \% \mathrm{CI})$ & 36.8 (35.0 to 38.6$)$ & 34.5 (34.3 to 34.7$)$ & 37 (34.9 to 39.1$)$ & $34.4(34.3$ to 34.5$)$ & 36.9 (35.5 to 38.3$)$ & 34.5 (34.3 to 34.6$)$ \\
\hline $\mathrm{p}$ value & $<0.02$ & & $<0.002$ & & $<0.001$ & \\
\hline
\end{tabular}

$(\mathrm{p}<0.05)$. Of these children $84.2 \%$ were legitimate, compared with $61.8 \%$ of the total $(\mathrm{p}<0.001)$. They were more likely to have an older mother $(\mathrm{p}=0.001)$, be later in the birth order $(p=0.009)$, and longer $(p=0.007)$. There was no difference in social class distribution between the two groups.

BIRTH CHARACTERISTICS AND MENTAL ABILITY Mean (SD) scores on MHT test for each category of birth measurements are reported (table 3), both uncorrected, and then corrected for gestational age, maternal age, parity, social class, and legitimacy. Here we also report the correlation corrected only for social class. Birth weight was significantly related to the Moray House Test score (uncorrected: male $r=0.15, \mathrm{p}=0.02$; female $r=0.21$, $\mathrm{p}=0.03$; total $r=0.17, \mathrm{p}<0.001$; corrected for social class $(\mathrm{n}=395)$ : male partial $r=0.21, \mathrm{p}=0.02$; female partial $r=0.22$, $\mathrm{p}=0.02$; total partial $r=0.22, \mathrm{p}<0.001$; corrected as above $(\mathrm{n}=295)$ : male partial $r=0.23, \mathrm{p}=0.003$; female partial $r=0.27$, $\mathrm{p}=0.002$; total partial $r=0.25, \mathrm{p}<0.001)$, as was birth length (corrected as above: male partial $r=0.11, \mathrm{p}=0.14$; female partial $r=0.17, \mathrm{p}=0.05 ;$ total partial $r=0.14$, $\mathrm{p}=0.01)$. Birth length was no longer significant when controlled for birth weight (birth weight and length were significantly correlated; $r=0.54, \mathrm{p}<0.0001)$. The weight of a baby is a crude summary of its physique, and the body proportions of the baby may be better described using the ponderal index (birth weight/length ${ }^{3}$ ), with a low ponderal index indicating thinness. ${ }^{2}$ This measure of body proportion has been more predictive of later disease than birth weight alone in some studies. $^{2}$ There was no significant relation between ponderal index and MHT score. Neither placental weight nor umbilical cord length was significantly related to test score, nor was the birth/placental weight ratio. Social class was significantly correlated with MHT score (male $r=-0.33, \mathrm{p}<0.001$; female $r=-0.18$, $\mathrm{p}=0.01$; total $r=-0.26, \mathrm{p}<0.001)$, but birth weight was not directly correlated with social class $(r=-0.08, \mathrm{p}=0.12)$. There was no significant change in the results when the data were reanalysed excluding high birth weights, which was done to test for a decrease in score at the highest birth weights (correlation between birth weight and MHT was: all subjects, $r=0.24, \mathrm{p}<0.001 ; \mathrm{n}=449$; excluding births $>4200 \mathrm{~g}, r=0.24, \mathrm{p}<0.001$; $\mathrm{n}=426)$.

\section{MATERNAL CHARACTERISTICS AND MENTAL}

ABILITY

MHT scores related to maternal characteristics (table 4) show that children born legitimately had higher test scores (mean 36.9 (SD 14.9) v 31.0 (SD 15.3); $p<0.001)$. Increasing maternal age was significantly related to higher MHT test scores at age 11 for females only $(r=0.20, \mathrm{p}=0.005 ;$ Spearman's $r=0.21$, $\mathrm{p}=0.002$; the distribution of maternal age was positively skewed), but not when corrected for legitimacy. The distribution of maternal parity was skewed, and it showed no significant correlation with MHT scores using non-parametric tests (Spearman's $r=-0.07$, $\mathrm{p}=0.13)$.

\section{MULTIVARIATE ANALYSES}

Multivariate linear regression showed that five predictors contributed significant and partly independent variance to Moray House Test scores: social class, birth weight, age at MHT test, maternal parity, and illegitimacy. Sex, birth length, maternal age, and gestational age were excluded as not contributing independently to the model when the former variables were entered. The five variables account for $15.6 \%$ of the variance (adjusted $\mathrm{R}^{2}$ ) in the test score age 11 . Social class contributes $6.6 \%(\beta$ $-0.26)$, birth weight a further $3.8 \%(\beta 0.20)$, age $2.4 \%(\beta 0.16)$, parity $2.0 \%(\beta-0.15)$, and

Table 2 Comparison of groups born in the Royal Maternity and Simpson's Memorial Hospital whose MHT scores were traced with those whose scores Table 2 Compar
were not traced

\begin{tabular}{|c|c|c|c|c|c|c|}
\hline Variable & $\begin{array}{l}\text { MHT scores traced } \\
\text { Mean }(95 \% \mathrm{CI})\end{array}$ & $n^{\star}$ & $\begin{array}{l}\text { MHT scores not traced } \\
\text { Mean }(95 \% \mathrm{CI})\end{array}$ & $n$ & $\begin{array}{l}\text { Difference in means } \\
(95 \% \mathrm{CI})\end{array}$ & $p$ value $\neq$ \\
\hline Maternal age (y) & $27.0(26.4$ to 27.6$)$ & 449 & 25.7 (25.2 to 26.2$)$ & 534 & $1.3(0.5$ to 2.0$)$ & 0.001 \\
\hline Parity & $2.4(2.2$ to 2.6$)$ & 449 & $2.05(1.9$ to 2.2$)$ & 536 & $0.3(0.09$ to 0.6$)$ & 0.009 \\
\hline Gestation (wk) & $39.4(39.1$ to 39.7$)$ & 339 & $39.6(39.4$ to 39.8$)$ & 432 & $0.2(-0.5$ to 0.2$)$ & 0.35 \\
\hline Days old & 3984 (3974 to 3994$)$ & 449 & 3989 (3980 to 3998$)$ & 536 & $5(-17.2$ to 8.7$)$ & 0.52 \\
\hline Birth weight $+(\mathrm{g})$ & 3317 (3267.5 to 3366.5$)$ & 449 & 3281 (3239.4 to 3322.6$)$ & 536 & $36(-28.1$ to 101.3$)$ & 0.26 \\
\hline Birth length (cm) & $50.6(50.3$ to 50.9$)$ & 428 & $50.1(49.9$ to 50.3$)$ & 503 & $0.5(0.14$ to 0.86$)$ & 0.007 \\
\hline Placental weight (g) & $658.8(632.1$ to 685.5$)$ & 124 & $641.6(618.1$ to 665.1$)$ & 113 & $17.2(-28.5$ to 43.1$)$ & 0.69 \\
\hline Umbilical cord length $(\mathrm{cm})$ & $56.7(54.6$ to 58.8$)$ & 121 & $54.0(52.2$ to 55.8$)$ & 109 & $2.7(0$ to 5.5$)$ & 0.06 \\
\hline Ponderal index $\left(\mathrm{kg} / \mathrm{m}^{3}\right)$ & $25.6(25.2$ to 26.0$)$ & 428 & $26.1(25.8$ to 26.4$)$ & 503 & $0.5(-0.002$ to 1.0$)$ & 0.07 \\
\hline
\end{tabular}

* Total number of subjects for each variable is not always 449 because of missing data. †Original data converted to metric: $1 \mathrm{oz}=28 \mathrm{~g}, 1 \mathrm{inch}=2.5 \mathrm{~cm}, 1 \mathrm{lb}=453 \mathrm{~g}$.

$\ddagger$ Calculated by paired $t$ test on continuous variables. 
Table 3 Mean (SD) score in Moray House Test according to birth weight and other variables

\begin{tabular}{|c|c|c|c|c|c|c|c|c|c|c|c|c|c|}
\hline \multirow[b]{2}{*}{ Variables } & \multicolumn{4}{|l|}{ Male } & \multicolumn{4}{|c|}{ Female } & \multicolumn{5}{|l|}{ Total } \\
\hline & No. & Mean (SD) & Partial rt & $p$ & No. & Mean (SD) & Partial rt & $p$ & No. * & Mean (SD) & $r$ & Partial rt & $p$ \\
\hline \multicolumn{14}{|c|}{ Birth weight (g) } \\
\hline$<2500$ & 9 & $30.8(19.3)$ & & & 16 & $30.5(20.1)$ & & & 25 & $30.6(19.4)$ & & & \\
\hline $2501-3000$ & 50 & $35.5(13.8)$ & & & 52 & $33.4(16.1)$ & & & 102 & $34.4(15.0)$ & & & \\
\hline $3001-3500$ & 90 & $35.6(14.7)$ & & & 74 & $39.4(14.4)$ & & & 164 & $37.3(14.6)$ & & & \\
\hline $3501-4000$ & 62 & $37.2(15.3)$ & & & 53 & $38.4(14.1)$ & & & 115 & $37.8(14.7)$ & & & \\
\hline $4001-4500$ & 28 & $44.9(10.6)$ & & & 6 & $43.7(11.5)$ & & & 34 & $44.7(10.6)$ & & & \\
\hline$>4500$ & 7 & $34.1(10.5)$ & & & 2 & $38.5(3.5)$ & & & 9 & $35.1(9.4)$ & & & \\
\hline Total & 246 & $36.8(14.5)$ & 0.23 & 0.003 & 203 & $37.0(15.4)$ & 0.27 & 0.002 & 449 & $36.9(14.9)$ & 0.17 & 0.25 & $<0.001$ \\
\hline \multicolumn{14}{|c|}{ Birth length (cm) } \\
\hline$<50$ & 58 & $35.9(13.6)$ & & & 66 & $34.4(17.5)$ & & & 124 & $35.1(15.8)$ & & & \\
\hline $50-52.4$ & 79 & $35.7(14.6)$ & & & 63 & $37.5(14.7)$ & & & 142 & $36.5(14.6)$ & & & \\
\hline$>52.5$ & 96 & $38.0(14.9)$ & & & 66 & $39.0(13.2)$ & & & 162 & $38.4(14.2)$ & & & \\
\hline Total & 233 & $36.7(14.4)$ & 0.11 & 0.014 & 195 & $37.0(15.3)$ & 0.17 & 0.05 & 428 & $36.8(14.8)$ & 0.11 & 0.14 & 0.01 \\
\hline \multicolumn{14}{|c|}{ Placental weight (g) } \\
\hline$\leqslant 500$ & 13 & $31.3(14.0)$ & & & 5 & $26.8(7.2)$ & & & 18 & $30.1(12.4)$ & & & \\
\hline $501-600$ & 23 & $35.6(13.2)$ & & & 14 & $33.7(20.9)$ & & & 37 & $34.9(16.3)$ & & & \\
\hline$>600$ & 38 & $39.9(14.2)$ & & & 30 & $36.2(15.0)$ & & & 68 & $38.3(14.6)$ & & & \\
\hline Total & 74 & $37.0(14.1)$ & 0.18 & 0.16 & 49 & $34.5(16.3)$ & 0.06 & $0.72 \ddagger$ & 123 & $36.0(15.0)$ & 0.15 & 0.09 & 0.34 \\
\hline \multicolumn{14}{|c|}{ Umbilical cord length $(\mathrm{cm})$} \\
\hline$<55$ & 41 & $36.4(12.7)$ & & & 24 & $30.3(15.2)$ & & & 65 & $34.1(13.9)$ & & & \\
\hline $55-62.5$ & 20 & $38.0(15.0)$ & & & 13 & $37.0(16.4)$ & & & 33 & $37.6(15.3)$ & & & \\
\hline$>62.5$ & 12 & $37.6(18.2)$ & & & 10 & $38.8(15.3)$ & & & 22 & $38.1(16.6)$ & & & \\
\hline Total & 73 & $37.0(14.2)$ & 0.06 & 0.64 & 47 & $33.9(15.7)$ & 0.28 & $0.07 \ddagger$ & 120 & $35.8(14.8)$ & 0.12 & 0.13 & 0.17 \\
\hline \multicolumn{14}{|c|}{ Ponderal index $\left(\mathrm{kg} / \mathrm{m}^{3}\right)$} \\
\hline$<24$ & 70 & $35.2(15.9)$ & & & 82 & $36.4(15.9)$ & & & 152 & $35.8(15.9)$ & & & \\
\hline $24-25.4$ & 53 & $37.4(11.8)$ & & & 33 & $37.4(16.6)$ & & & 86 & $37.4(13.8)$ & & & \\
\hline $25.5-27.9$ & 54 & $36.6(15.4)$ & & & 38 & $38.1(14.0)$ & & & 92 & $37.2(14.8)$ & & & \\
\hline$\geqslant 28$ & 56 & $37.9(14.0)$ & & & 42 & $36.8(14.6)$ & & & 98 & $37.4(14.2)$ & & & \\
\hline Total & 233 & 36.7 (14.4) & 0.01 & 0.94 & 195 & $37.0(15.3)$ & 0.03 & 0.71 & 428 & $36.8(14.8)$ & 0.02 & 0.02 & 0.69 \\
\hline
\end{tabular}

* Total number of subjects for each variable is not 449 because of missing data, number of subjects for partial $r$ ranges from 110 to 295 because of missing data and exclusion of extreme outliers: placental weight $<180>1400$ g; umbilical cord length $>110 \mathrm{~cm}$; gestational age $<21>58$ weeks; birth length $<37>62 \mathrm{~cm}$. + Corrected for gestational age, maternal age, parity, social class, and legitimacy. ‡Corrected for gestational age, maternal age, parity, and social class. \Original data converted to metric: $1 \mathrm{oz}=28 \mathrm{~g}, 1 \mathrm{inch}=2.5 \mathrm{~cm}, 1 \mathrm{lb}=453 \mathrm{~g}$.

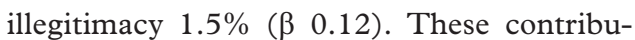
tions are all significant at the $\mathrm{p}<0.001$ level, except illegitimacy $(\mathrm{p}=0.009)$. Birth weight therefore accounts for $3.8 \%$ of the variance of IQ at age 11, a small, but highly significant, effect size. The relation persists when "low birth weight" babies ( $<2500 \mathrm{~g}$; $\mathrm{n}=25$ ) were excluded (contribution to variance: total $15.5 \%$, of which social class $7.9 \%$, birth weight $2.4 \%$, illegitimacy $2.4 \%$, age at MHT test date $2.2 \%$, and parity $1.7 \%$; all $\mathrm{p}<0.002$ except parity $\mathrm{p}=0.007$ ).
Structural equation modelling was performed to compare the fit of the data with two competing hypotheses. (1) A regression model which posits that social class and birth weight significantly but independently contribute variance to cognitive ability. (2) A mediating variables model in which the effect of social class on cognitive ability at age 11 is mediated (partly or completely) via birth weight (fig 1). The regression model provides the best fit for the data, showing that birth weight, social class and age all contribute variance independently

Table 4 Mean (SD) score in Moray House Test according to maternal variables studied

\begin{tabular}{|c|c|c|c|c|c|c|c|c|c|c|c|c|}
\hline & \multicolumn{4}{|c|}{ Male } & \multicolumn{4}{|c|}{ Female } & \multicolumn{4}{|l|}{ Total } \\
\hline & No. & Mean (SD) & $r$ & $p$ & No. & Mean (SD) & $r$ & $p$ & No. * & Mean (SD) & $r$ & $p$ \\
\hline \multicolumn{13}{|l|}{ Gestational age } \\
\hline$<37$ weeks & 27 & $34.6(14.1)$ & & & 17 & $39.2(13.3)$ & & & 44 & $36.4(13.8)$ & & \\
\hline $37-42$ weeks & 141 & $38.0(14.6)$ & & & 119 & 37.9 (15.7) & & & 260 & $38.0(15.1)$ & & \\
\hline$>42$ weeks & 21 & $36.4(13.2)$ & & & 14 & $31.3(18.1)$ & & & 35 & $34.3(15.3)$ & & \\
\hline Total & 189 & $37.3(14.4)$ & 0.09 & 0.21 & 150 & 37.5 (15.7) & 0.03 & 0.69 & 339 & $37.4(15.0)$ & 0.06 & 0.24 \\
\hline \multicolumn{13}{|l|}{ Maternal age } \\
\hline$<25$ & 120 & $36.8(14.7)$ & & & 98 & $34.5(14.4)$ & & & 218 & $35.7(14.6)$ & & \\
\hline $25-29$ & 54 & $37.8(12.6)$ & & & 43 & 35.7 (14.4) & & & 97 & 36.9 (13.4) & & \\
\hline$>29$ & 72 & $36.2(15.7)$ & & & 62 & $41.9(16.5)$ & & & 134 & $38.8(16.3)$ & & \\
\hline Total & 246 & $36.8(14.5)$ & 0.01 & 0.90 & 203 & $37.0(15.4)$ & 0.20 & 0.005 & 449 & 36.9 (14.9) & 0.10 & $0.038+$ \\
\hline \multicolumn{13}{|l|}{ Parity } \\
\hline 0 & 114 & $38.2(15.4)$ & & & 109 & $37.1(15.4)$ & & & 223 & $37.6(15.4)$ & & \\
\hline $1-2$ & 79 & $37.1(14.1)$ & & & 60 & $38.3(13.6)$ & & & 139 & $37.6(13.9)$ & & \\
\hline $3-4$ & 22 & $33.5(10.6)$ & & & 19 & $32.8(17.6)$ & & & 41 & $33.2(14.1)$ & & \\
\hline$>4$ & 31 & $33.6(14.4)$ & & & 15 & $36.7(19.3)$ & & & 46 & $34.6(16.0)$ & & \\
\hline Total & 246 & $36.8(14.5)$ & -0.14 & 0.03 & 203 & $37.0(15.4)$ & -0.04 & 0.58 & 449 & $36.9(14.9)$ & $-0.07 \ddagger$ & 0.13 \\
\hline \multicolumn{13}{|l|}{ Legitimacy } \\
\hline Legitimate & 204 & $38.4(14.2)$ & & & 174 & $37.6(15.1)$ & & & 378 & $38.0(14.6)$ & & \\
\hline Illegitimate & 42 & $29.5(14.2)$ & & & 29 & $33.4(16.7)$ & & & 71 & $31.1(15.3)$ & & $0.001 \S$ \\
\hline
\end{tabular}

*Total number of subjects for each variable is not 449 because of missing data and exclusion of extreme outliers: gestational age $<21>58$ weeks. †Spearman's $r$ male $0.04, \mathrm{p} 0.52$; female 0.21 , p 0.002; total 0.12, p 0.009 .

$\ddagger$ Spearman’s $r$.

St test. 
Regression model

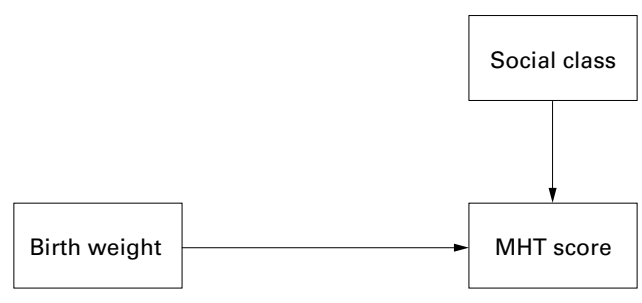

Mediating model

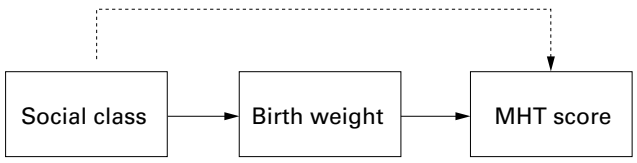

Figure 1 Two competing models of the associations among birth weight, social class, and MHT scores. The regression model hypothesises independent effects of parental social class and birth weight on IQ. The mediating model hypothesises that birth weight acts as a partial or total mediator of the inference of parental social class on later $I Q$ score.

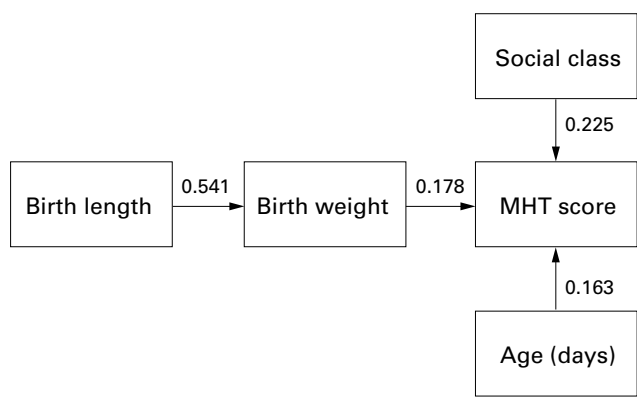

Figure 2 Best fitting model of the associations among birth weight, parental social class, and $I Q$ at age 11 years. Model fitting was performed using $E Q S .{ }^{20}$ Note that parental social class, birth weight, and age at test date have independent influences on age 11 IQ. The effect of birth length is entirely mediated by birth weight. The numbers adjacent to arrows are parameter weights estimated by $E Q S$; squaring them gives the variance shared by adjacent variables. This model has comprehensively good fit statistics.

to Moray House Test score age 11 (fig 2). The model shown in fig 2 has comprehensively good fit statistics, as follows: the average off diagonal absolute standardised residuals was 0.038 (the model accounts for most of the covariance among the variables shown); the model $\chi^{2}$ was 8.86, $\mathrm{df}=6, \mathrm{p}=0.18$ (nonsignificant $\chi^{2}$ values indicate well fitting models); Bentler-Bonett normed fit index $=0.953$, Bentler-Bonett non-normed fit index $=0.973$, comparative fit index $=0.984$ (values above 0.9 indicate well fitting models); all parameter weights in the model were significant; the Wald test found no parameters that might be dropped and the Lagrange multiplier test found no additional parameters that might improve the model (neither a more nor less economical model fits better than the one shown). Models in which birth weight acted as a mediator of social class had poor fit statistics (details available from the authors).

\section{Discussion}

In this cohort social class, birth weight, age, pregnancy number, and legitimacy of birth contribute some non-overlapping predictive power to cognitive function age 11 years. Birth weight and social class explain the largest amount of the variance, are not significantly correlated, and each make an independent contribution to IQ at age 11 . Birth weight explains $3.8 \%$ of the variance in IQ at age 11 , and social class accounts for $6.6 \%$ of the variance. These are small but significant effect sizes, and it is clear how large a proportion of the variance remains unexplained by these factors. Importantly, the relations in this cohort exist across the normal range of birth weight and mental ability. The reduced cognitive test scores at high birth weights seen in previous studies were not statistically significant here. Our findings agree with those of Seidman and colleagues, ${ }^{10}$ Sorenson and colleagues, ${ }^{9}$ and Richards and colleagues ${ }^{8}$ that birth weight and social class can explain a proportion of the variance in later psychometric intelligence. Martyn and colleagues ${ }^{11}$ found this relation to be not statistically significant, but used an indirect estimate of early life intelligence.

The fact that the relation between birth weight and childhood mental ability is observed over distinct historical periods implies that it is robust, making it tenable that mechanisms have remained unchanged over time. Data from historical studies can thus provide valuable information about early life predictors of disease, which are still relevant today. $^{23}{ }^{14}$ Moreover, a major strength of this cohort is the ability to compare performance on cognitive testing with almost the entire Scottish population born in the same year. This allows us to put the scores for the sample in the context of the whole 1921 born population. The subjects were both male and female, and particularly well characterised, allowing correction for gestational age, placental weight, and social factors. The well defined, narrow cultural epoch minimised variation in external, cohort specific influences on cognitive development.

As in other cohort series, however, there is significant loss to follow up. The main difficulty was in ascertaining the correct test record for illegitimate births, probably because the child's name was changed by marriage or adoption (formal and informal). This may explain why the test scores that were traced were significantly better than the general population, as illegitimate children were likely to be brought up in relatively deprived environments, and thus perform less well, but they are, nonetheless, comparable with the entire Scottish population tested in 1932 .

The suggestion that birth weight is merely a marker of social deprivation is not supported here. There is no direct correlation between birth weight and social class, replicating the 
result from previous studies of the programming hypothesis, ${ }^{21}$ and modelling confirmed that the effect of social class was not mediated by birth weight. Having shown independent associations among birth weight, social class, and childhood mental ability, it is now important to investigate potential mechanisms. This study did not address these. Birth weight and social class are crude markers of fetal development and the environment in which a child develops, and the underlying mechanism of their influence on childhood intelligence is unclear. The programming hypothesis has suggested that shortage of specific nutrients at critical stages of development may be responsible for the relation between birth weight and mental ability, ${ }^{9}$ and the timing of these insults on the developing brain is likely to be important. ${ }^{4}$ Neurochemical influences such as insulin like growth factors have also been implicated. ${ }^{8}$ Ongoing deprivation throughout life, for which social class at birth is a poor approximation, ${ }^{14}$ plays a significant role in determining outcome. ${ }^{12}$

The relative importance of different early life influences might have changed since the 1920 s. This could affect the relation between early life factors and later intelligence in many ways. For example, high infant mortality means that the effect of selective influences on survival was greater. In 1921,115 per 1000 children died by the age of $10^{22}$ (in 2000 the mortality rate was less than 6 per $1000^{23}$ ), and a large proportion of these might have had relatively low birth weights. This would tend to decrease the strength of any relation between birth weight and mental ability. Furthermore, the study population was born in hospital, at a time when the majority of births occurred at home. A large proportion of these births was illegitimate and, although this explains some of the differences between the sample and the population, it does not explain the relations seen within the sample itself. The proportion of births registered to unmarried mothers in Scotland in 1921 was $7.1 \%,{ }^{22}$ compared with $42.6 \%$ in $2000 .{ }^{23}$ Seven per cent, however, were registered by the mother alone, implying a similar proportion of unsupported single mothers as in 1921, although the social impact of an illegitimate birth is likely to have changed considerably. Furthermore, the prevalence of breast feeding, an important factor in physical and mental development, ${ }^{24}$ has fallen dramatically in the past 79 years, from $80 \%$ to $55 \%$ at 10 days, and from $50 \%$ to $19 \%$ at 6 months. ${ }^{1423}$ There continues to be concern about children's nutrition, and the wider environment in which many children are raised. General standards of housing have improved, with less overcrowding, but many children are raised in areas of deprivation with poor housing. The degree of social inequality in Scotland today means that postnatal influences may be more variable across communities than across time. ${ }^{25}$

Social class has been seen as a broad indicator for a range of socioeconomic influences and, therefore, in previous studies, controlling for social class was thought to control for confounding by other social factors. ${ }^{14} \mathrm{~A}$ recent study that also examined Scottish children in 1921, however, showed that social class derived from paternal occupation may not adequately describe the environmental influences on the developing child. ${ }^{14}$ Furthermore, variation in income is greater within the bands of social class than between them. ${ }^{24}{ }^{26}$ Therefore, the contribution of social class to mental ability is likely to have been underestimated, partly also because of the narrow range of social class in this sample. The wider socioeconomic environment ${ }^{27}$ may therefore explain a proportion of the unexplained variance in mental ability scores. Other influences include genetic factors, which account for $40-70 \%$ of the variance in mental test scores. ${ }^{27}$ Also, birth weight is a very crude marker of fetal growth and nutrition, and other measures of intrauterine influences such as head size may be important, ${ }^{11}$ but were not available to us.

Although health care today differs significantly from the period studied, these historical data are important for future studies, not least because they show that the association between early life factors and childhood mental ability holds across distinct cohorts. Moreover, the historical nature of this data provides an opportunity to study this cohort in detail now, in old age, to relate their childhood data to their current health and cognition, at a time in their lives when these are critical.

SDS is funded by an MRC Clinical Training Fellowship. AP is funded by the BBSRC. MAR is funded by the Scottish Office. Construction of a database of Scottish Mental Survey Test results is supported by the Chief Scientist Office of the Scottish Executive and a BBSRC SAGE grant. We are grateful to the Scottish Council for Research in Education for access to all the Scottish Mental Survey Test scores. We also thank Dr Michael Scol Barfoot and assistance with, the birth records, wrote the first draft of the paper, and coordinated revisions. JMS, IJD, and LMW conceived the original idea for the study. JMS and IJD participated in interpretation of results. IJD performed structural equation modelling. MAR collected the birth record data and entered it into a database. AP collected the data from the Scottish Mental Survey, entered it into a database, and performed initial statistical analysis. MAR and AP performed the matching of birth and Scottish Mental Survey perfo IDD JMS AP, MAR and LJW contributed Mental Survey data. IJD, JMS, AP, MAR, and LJW
the paper. IJD will act as guarantor.

1 Bouchard TJ Jr. Genetic and environmental influences on adult intelligence and special mental abilities. Hum Biol 1998;70:257-79.

2 Barker DJP. Maternal nutrition, fetal nutrition, and disease in later life. Nutrition 1997;13:807-13.

3 Barker DJP. Mothers, babies and disease in later life. London: BMJ Publishing Group, 1994.

4 Morgane PJ, Austin-LaFrance R, Bronzino J, et al. Prenatal malnutrition and development of the brain. Neurosci Biobehav Rev 1993;17:91-128.

5 Drillien CM. The incidence of mental and physical handicaps in school age children of very low birth weight. II. Pediatrics 1967;39:238-47.

6 Rose SA, Feldman JF. Prediction of IQ and specific cognitive abilities at 11 years from infancy measures. Dev Psychol 1995;31:685-96.

7 Hutton JL, Pharoah PO, Cooke RW, Stevenson RC. Differential effects of preterm birth and small gestational age on cognitive and motor development. Arch Dis Child Fetal Neonatal Ed 1997;76:F75-F81.

8 Richards M, Hardy R, Kuh D, Wadsworth ME. Birth weight and cognitive function in the British 1946 birth cohort: longitudinal population based study. BMF 2001;322:199203. 
9 Sorensen HT, Sabroe S, Olsen J, et al. Birth weight and cognitive function in young adult life: historical cohort study [published erratum

10 Seidman DS, Laor A, Gale R, et al. Birth weight and intellectual performance in late adolescence. Obstet Gynecol 1992;79:543-6.

11 Martyn CN, Gale CR, Sayer AA, Fall C. Growth in utero and cognitive function in adult life: follow up study of people born between 1920 and 1943. BMF 1996;312:1393-6.

12 Hack $M$. Effects of intrauterine growth retardation on mental performance and behavior, outcomes during adolescence and adulthood. Eur f Clin Nutr 1998;52(suppl 1):S65-S70.

13 Bartley M, Power C, Blane D, et al. Birth weight and later socioeconomic disadvantage: evidence from the 1958 British cohort study. BMF 1994;309:1475-8.

14 Baxter-Jones AD, Cardy AH, Helms PJ, et al. Influence of socioeconomic conditions on growth in infancy: the 1921 socioeconomic conditions on growth in infancy: the

15 Kramer MS, Seguin L, Lydon J, Goulet L. Socio-economic disparities in pregnancy outcome: why do the poor fare so poorly? Paediatr Perinat Epidemiol 2000;14:194-210.

16 Wiener G. The relationship of birth weight and length of gestation to intellectual development at ages 8 to 10 years. f Pediatr 1970;76:694-9.

17 Moore VM, Miller AG, Boulton TJ, et al. Placental weight, birth measurements, and blood pressure at age 8 years. Arch Dis Child 1996;74:538-41.

18 Deary IJ, Whalley LJ, Lemmon $\mathrm{H}$, et al. The stability of individual differences in mental ability from childhood to old age: follow-up of the 1932 Scottish Mental Survey. Intelligence 2000;28:49-55.

19 The Scottish Council For Research in Education. The intelligence of scottish children. A national survey of an age group. London: University of London Press, 1933.

20 Bentler PM. EQS Structural Equations Program Manual. Encino, CA: Multivariate Software, Inc., 1995.

21 Fall CH, Vijayakumar M, Barker DJ, et al. Weight in infancy and prevalence of coronary heart disease in adult life. $B M \mathcal{F}$ and prevalence of

22 67th Annual Report of the Registrar General for Scotland, 1921. London: HMSO, 1921

232000 Preliminary Return, Population and Vital Events, Scotland. Edinburgh: General Register Office for Scotland, 2001.

24 Lanting CI, Fidler V, Huisman M, et al. Neurological differences between 9-year-old children fed breast-milk or formula-milk as babies. Lancet 1994;344:1319-22.

25 Macintyre S. The Black Report and beyond: what are the issues? Soc Sci Med 1997;44:723-45.

26 Joseph KS, Kramer MS. Review of the evidence on fetal and early childhood antecedents of adult chronic disease. Epidemiol Rev 1996;18:158-74.

27 Cleveland $\mathrm{HH}$, Jacobson KC, Lipinski JJ, Rowe DC. Genetic and shared environmental contributions to the relationship between the home environment and child and adolescent achievement. Intelligence 2000;28:69-86.

\section{Commentary}

The hypothesis that nutritional factors may programme the fetus and influence the risk of subsequent death or morbidity is of considerable public health significance. There is a wide range and variety of adult disability that may be attributable to fetal and early child development. ${ }^{1}$ The past quarter century has seen important developments in the care of the neonate with a corresponding improvement in survival of ever smaller infants. This has generated questions on the quality of survival, not only in relation to overt clinical disability but also in more subtle and subclinical deficits of cognitive and motor function. To be able to obviate or ameliorate these deficits, the differential contribution of intrauterine growth restriction as a marker of fetal malnutrition, preterm delivery, and social and other environmental factors acting pre- or postnatally, is needed. Difficulty in disentangling the relative contribution made to cognitive and other deficits arises because these several influences are highly correlated and because cause and effect cannot be assumed.

Several geographically defined population cohort studies, examining cognitive development in relation to birth weight, have focused on a comparison of low and normal birth weight infants and found that the low birth weight infants do not perform as well as their normal birth weight controls. ${ }^{2-4}$ Within the low birth weight infant group, differential effects of small for gestational age, preterm delivery, and social factors have also been observed in relation to cognitive function. ${ }^{5}$ The association of birth weight and later cognitive function among infants of all birth weights is not clear cut. One study found no significant association, ${ }^{6}$ while another concluded that fetal growth may influence subsequent adult cognitive function.

The study reported by Shenkin et al uses a historical cohort born in 1921 and found independent associations of birth weight and social class with cognitive function assessed when the cohort was aged 11 years. Although birth weight and social class had independent effects in a multiple regression, a statistical model of birth weight acting as a mediator of social class had a poor fit. The authors have done well to link successfully almost $50 \%$ of the birth and mental test result records as so long a time has elapsed. Nevertheless, the problem of nonresponse bias must be considered in assessing the validity of the observations.

The fundamental question all these studies endeavour to answer is whether the cerebral impairment is prenatal or postnatal in timing and whether environmental factors, of which social class is a surrogate measure, have an important influence. Possible preventive and remedial measures will be dependent on the answers to these questions. One caveat that should be borne in mind, concerns the tests that are used to assess cognitive function. What do these tests actually measure? Ideally they measure innate mental ability, whatever that is, at a point in time. However, in spite of efforts to design tests that are "culture free", none meet this criterion, whether it is the Moray House Test as used by the authors in this study, the Wechsler Intelligence Scale for Children, the Goodenough Draw-a-Man test, or any other measure of cognitive function. Social class differences in cognitive performance tests are culture dependent and it should not be inferred that these are attributable to differences in intellectual capacity or to cerebral impairment. For example, children who have limited access to pencil and paper are likely to perform less well on the draw-a-man test than those with better resources, irrespective of their cognitive ability. The social class cultural effect on tests of cognitive ability may overshadow the social class effect mediated through birth weight.

Shenkin et al have provided valuable data that will inform the debate in this important field but the debate is likely to continue for years to come.

EMERITUS PROFESSOR P O D PHARAOH FSID Unit of Perinatal and Paediatric Epidemiology, Dept of Pubic Health, Muspratt Building, Liverpool L69 3GB, UK

1 Barker DJP, ed. Fetal and infant origins of adult disease. London: BMJ Publications, 1992 
2 Lloyd BW, Wheldall K, Perks D. Controlled study of intelligence and school performance of very low-birth-weight children from a defined geographical area. Dev Med Child Neurol 1988,30.36-42.

3 Abel Smith AE, Knight-Jones EB. The abilities of very lowbirthweight children and their classroom controls. Dev Med Child Neurol 1990;32:560-601.

4 Pharoah POD, Stevenson CJ, Cooke RWI, Stevenson RJ. Clinical and subclinical deficits at 8 years in a geographically defined cohort of low birthweight infants. Arch Dis Child 1994;70:264-70.
5 Hutton JL, Pharoah POD, Cooke RWI, Stevenson RC. Differential effects of preterm birth and small for gestational age on cognitive and motor development. Arch Dis Child Fetal Neonatal Ed 1997,76:F75-F81.

6 Martyn CN, Gale CR, Sayer AA, Fall C. Growth in utero and cognitive function in adult life: follow up study of people born between 1920 and 1943. BMF 1966;312: 1393-6.

7 Sorensen HT, Sabroe S, Olsen J, et al. Birth weight and cognitive function in young adult life: historical cohort study. BMF 1997;315:401-3.

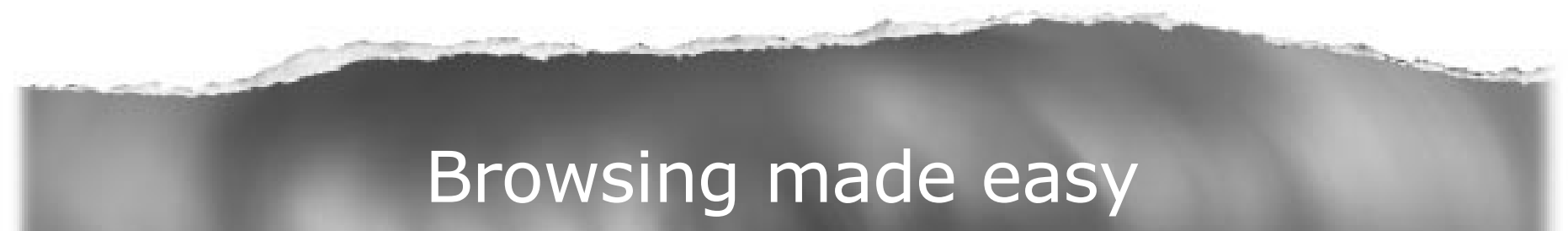

\section{Collections}

With a single click Collections allows you to find all articles that have been published in your chosen subject. Select from over 200 clinical and non-clinical topic collections and/or cross search other specialist journals, the BMJ and Cochrane Reviews

www.archdischild.com 